\title{
Curating and annotating a collection of traditional Irish flute recordings to facilitate stylistic analysis
}

\author{
Münevver Köküer ${ }^{1}$ • Islah Ali-MacLachlan² - Daithí Kearney ${ }^{3}$ • Peter Jančovič ${ }^{1}$
}

Received: 29 January 2016 / Revised: 1 February 2019 / Accepted: 4 February 2019 / Published online: 23 February 2019

(c) The Author(s) 2019

\begin{abstract}
This paper presents the curation and annotation of a collection of traditional Irish flute recordings to facilitate the analysis of stylistic characteristics. We introduce the structure of Irish tunes, types of tunes and the ornamentation, which is a decisive stylistic determinant in Irish traditional music. We identify seminal recordings of prominent flute players and provide information related to players and their style and geographical context. We describe the process of manual annotation of the audio data. The annotations consist of the onsets of notes, note frequency and identity of notes and ornaments. We also present initial stylistic analysis of individual players in terms of ornamentation and phrasing and provide a variety of statistics for the data. The ability to accurately represent and analyse stylistic features such as ornaments allow for the development of discourse related to several key ethnomusicological questions surrounding music making, musical heritage and cultural change.
\end{abstract}

Keywords Irish traditional music $\cdot$ Ornament $\cdot$ Style $\cdot$ Flute $\cdot$ Corpus $\cdot$ Annotation

\section{Introduction}

In Irish traditional music, tunes are usually of simple and regular structure; however, the tradition allows for and applauds the creativity of the individual musician. The creativity, musicality and style of musicians are expressed through variations in performance, with ornamentation being a decisive stylistic

This work was supported by the project 'Characterising Stylistic Interpretations through Automated Analysis of Ornamentation in Irish Traditional Music Recordings' under the 'Transforming Musicology' programme funded by the Arts and Humanities Research Council (UK).

Münevver Köküer

m.kokuer@bham.ac.uk

Islah Ali-MacLachlan

islah.ali-maclachlan@bcu.ac.uk

Daithí Kearney

daithi.kearney@dkit.ie

Peter Jančovič

p.jancovic@bham.ac.uk

1 Department of Electronic, Electrical and Systems Engineering, University of Birmingham, Birmingham, UK

2 Faculty of Computing, Engineering and the Built Environment, Birmingham City University, Birmingham, UK

3 Department of Creative Arts, Media and Music, Dundalk Institute of Technology, Dundalk, Ireland determinant in Irish traditional music. As Keegan [31,34,35] has noted, the discourse concerning style in Irish traditional music is undermined through the use of inadequate language that provides unclear descriptions and analysis of the music. In his series of books $[6,8,9]$, the collector and scholar Breathnach did not always notate ornaments in published transcriptions [29], recognising the limitations of notation in communicating aspects of style of the musicians from whom he collected. Thus, questions remain concerning the analysis of stylistic difference in Irish traditional music. Such analysis would inform significant debates among both academics and practitioners related to variances in individualistic and regional styles and acknowledgement of change over time in the tradition.

In order to answer the above questions, a large number of recordings including various performances by musicians should be collected, analysed, compared and contrasted. In this paper, we introduce our corpus on Irish traditional music to study aspects of style through ornamentation collected in the scope of the 'Transforming Musicology' project. $^{1}$ We

\footnotetext{
1 Transforming Musicology is funded under the Arts and Humanities Research Council (UK) Digital Transformations in the Arts and Humanities scheme. It seeks to explore how emerging technologies for working with music as sound and score can transform musicology, both as an academic discipline and as a practice outside the university (For more information, see [1]).
} 


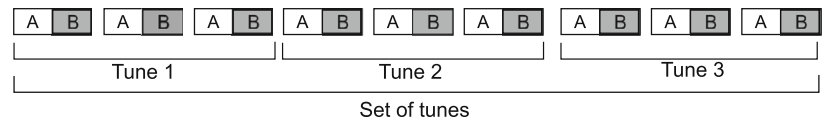

Fig. 1 An example of a graphical representation of a structure in Irish traditional music

identified prominent flute players in the Irish tradition and their repertoire of tunes that have been regularly recorded and performed. Initially, we populated the digital library for this project with commercially available recordings. These recordings are accessible, have been influential on the development of the tradition and would make the findings of the study more relevant to many within the Irish traditional music community, thus helping in the dissemination of the research. These recordings are drawn from a time span of nearly a century, include recordings of deceased musicians and provide some insights into variations in style between eras and geographical regions. The presented digital library is aimed to serve users in both the musicology and technology communities, from musicians to academics in this field to develop an understanding of style through the analysis of performances of a core repertoire by a variety of musicians. We have used a part of the library in our previous research $[3,4,24,36]$.

This paper starts by introducing in Sect. 2 the structure of Irish tunes, the types of tunes and ornaments. In Sect. 3, we describe studies of style in Irish traditional music. Section 4 introduces the selected flute players and gives geographical context. Section 5 describes the collection of recordings and metadata content in the library, providing information on note annotation process of the audio signal and structure of storing the annotations. It also presents initial stylistic analysis of individual players in terms of note durations, type and quantity of ornamentation used, phrasing and note occurrence statistics and also presents performance of a baseline automatic system for note onset detection. Section 6 presents summary of this work and outlines future directions and potential users of the library.

\section{Irish traditional music}

\subsection{The structure of tunes}

In the Irish tradition, the term 'tune' is used to refer to a melody that is usually composed of parts that may be repeated a number of times. Most tunes contain two parts and tunes with more parts are less common [7].

In the example shown in Fig. 1, each tune has two parts, denoted as an 'A' and a ' $\mathrm{B}$ ', typically containing eight bars of music in each. Very often a performer will choose three such tunes, usually in different key signatures, which are performed as a continuous piece of music, referred to as a 'set of tunes.' This is, in part, influenced by the desired length of a track, usually lasting three to four minutes. It is important that each tune in a set is identified. It may be noticeable that while some stylistic features, such as phrasing, are consistent, some ornaments may be used more or less regularly in different key signatures.

\subsection{Tune titles}

The titles of tunes within Irish traditional music often make reference to interesting facets of everyday life, taking their name from people, geographical locations or common undertakings, pastimes or situations [19,23,62]. Jim Donoghue's, Maurice O'Keeffe's and McGivney's Fancy refer to specific people, while the protagonists in The Girl in the Big House, The Kerry Man and The Maid on the Green remain nameless. Groups of people from a particular area are commonly referred to as lads, lasses or maids as shown in Maids of Ardagh. Natural history is also popular as a subject area, with plants such as The Hawthorn, The Ashplant and The Flax in Bloom and animals like The Hare in the Heather and The Pigeon on the Gate. Geographical locations like The Humours of Ballyloughlin and The Church Street Polka are popular. While occasionally tunes have titles like the Edenderry Reel or the Church Street Polka, Hast and Scott [23] note that most titles do not describe the type of tune.

\subsection{Tune types}

The annotated recordings contain a number of tune types, namely Jigs, Reels, Hornpipes and Polkas. Many tunes had migrated from England and Scotland and underwent a process of being consolidated into Irish traditional music corpus over the eighteenth and nineteenth centuries [51]. According to O'Connor [49], most of Irish traditional music played now is dance music, but is more commonly played for listening. The music is "inextricably linked to dance" and can be characterised by its metric structure or the number of beats per measure [11, p. 90].

Playing tempo is generally defined by context. The origins of Irish traditional music lie in accompaniment of dancing during the eighteenth century, separating into its own concert tradition in America and Ireland during the nineteenth century [49]. This allowed tunes to be played at tempos which would not be suitable for dancing, but are effective on the concert stage.

It is unusual to find Irish traditional music played 'straight' or with all eighth notes identical in duration. Pairs of eighth notes in reels and hornpipes will often be 'swung' with a longer first note and a shorter second note. Rosinach and Traube [55] define swing as a ratio of these long and short note durations, where (1:1) is no swing and $(3: 1)$ is hard swing. They found that ratios of around (2:1) are common 
within Irish music. Larsen notes that classically trained musicians often find this swing or 'lilt' initially difficult to grasp because it is learned by immersion rather than analysis [38].

\subsubsection{The jig}

The jig is thought to be the oldest form of Irish traditional dance that is still in popular use. While the double jig is the most common form of jig, three other forms of jig exist, namely the single jig, slip or hop jig and the slide.

Hast and Scott [23] define the double jig as having a 6/8 time signature where the character of the melody is defined by two groups of three eighth notes. Mnemonic phrases are often used to aid learning of rhythm and both [11,23] describe the phrase "rashers and sausages" being used to describe the character of a double jig. The character of the single jig is based on a quarter note followed by an eighth note. An example of this is the popular song 'Pop goes the weasel.' The slip jig time signature of $9 / 8$ is categorised by three groups of three eighth notes. The slide is not as common as the other jigs and emanates from Sliabh Luachra, an area of Munster that borders Cork, Kerry and Limerick. Typically in a 12/8 time signature, the slide follows the rhythmic feel of a single jig with a significantly faster tempo [23].

\subsubsection{The reel}

The reel is the most common form of Irish traditional tune. Originating as the reill in Scotland during the sixteenth century, it had emerged in its modern form in Ireland during the eighteenth century. Older reels are typically of Scottish origin and many remain staples of the traditional corpus, but by the end of the eighteenth century, Irish reels were being printed as part of tune collections in Dublin [10,23].

The reel has a time signature of $4 / 4$ (common time), while the accents on the first and third notes in each bar give a feeling of $2 / 2$ (cut time). Williams [62] describes this as covering eight eighth notes in two groups of four in one bar of music.

\subsubsection{The polka}

As a dance, the polka developed in Czechoslovakia in the early 1800 s, emulating Polish dances and becoming widely fashionable in Europe. Upon its introduction to Ireland in the late 1800 s, it became particularly popular in the south-west of the country including Cork, Kerry and Limerick $[11,23,62]$.

The polka is written in 2/4 time and comes from the older single reel. According to Cooper [15], one bar of a polka will often consist of two groups of two quarter notes, with an accent on the second note of each pair. Unlike hornpipes and reels, polkas are not normally swung and all quarter notes are of equal length.

\subsubsection{The hornpipe}

While the edition of Playford's Dancing Master [53] published in 1651 contained a number of hornpipes, Brennan [11] believes the heavily swung hornpipe of the Irish traditions did not appear until the 1760s. During this time, there was also a change in time signature from $3 / 2$ (triple time) to $4 / 4$ [10]. O'Shea [51] discusses a typical traditional Irish tune repertoire in the 1870s as having undergone an expansion in the number of reels and hornpipes, no doubt in some part due to the related dance gaining popularity.

The hornpipe shares its $4 / 4$ meter with the reel, but it is characterised by a slower tempo and a heavily dotted or swung rhythm [23].

\subsection{Types of flute and flute key}

The flutes played in the recordings chosen for this corpus are mostly wooden pre-Boehm transverse flutes, the most popular choice of flute in Irish traditional music [17,22,60]. Most of the instruments are tuned with a lowest note $\mathrm{D}$ and measure approximately $60-68 \mathrm{~cm}$ in length, with a bore diameter of approximately $3 \mathrm{~cm}$ narrowing to $2.5 \mathrm{~cm}$ at the end farthest from the blow hole. Most have six primary open finger-holes, but many have up to eight keys ${ }^{2}$ to allow the musician to more easily play passages that might otherwise require complex cross-fingering patterns. While flutes played in the tradition can date back to the eighteenth century, a number of instrument makers have been making instruments targeted at Irish traditional musicians since the late 1970s [17,60].

\subsection{Ornamentation}

In Irish traditional music, ornaments are used as embellishments of the melodic line [38]. On the flute, they are usually created through the use of special fingered articulation. Their places are mostly not marked in the score, and the choice of their usage usually depends on performer's style. Ornaments can be categorised as single-note and multi-note ornaments.

\subsubsection{Single-note ornaments}

Single-note ornaments, namely 'cut' and 'strike', are pitch articulations. 'Cut' involves quickly lifting and replacing a finger from a tone hole and corresponds to a higher note than the ornamented note. 'Strike' is performed by momentarily closing an open hole and corresponds to a lower note than the ornamented note.

\footnotetext{
2 In this context, the word 'key' has two meanings: (1) the key signature or scale in which a tune is performed; (2) bright metal semitone levers attached to the flute.
} 

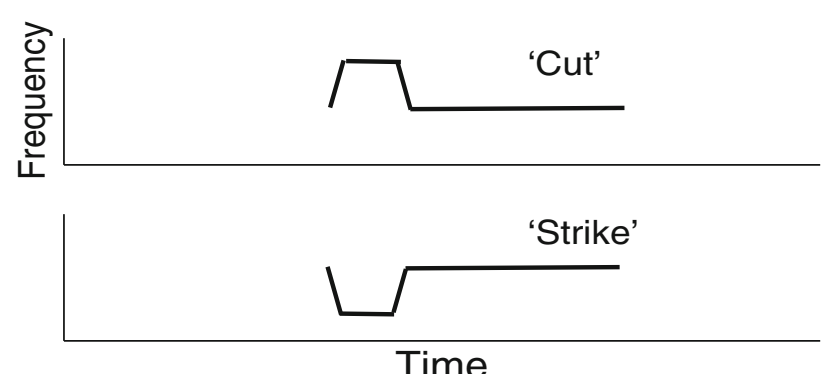

(a)
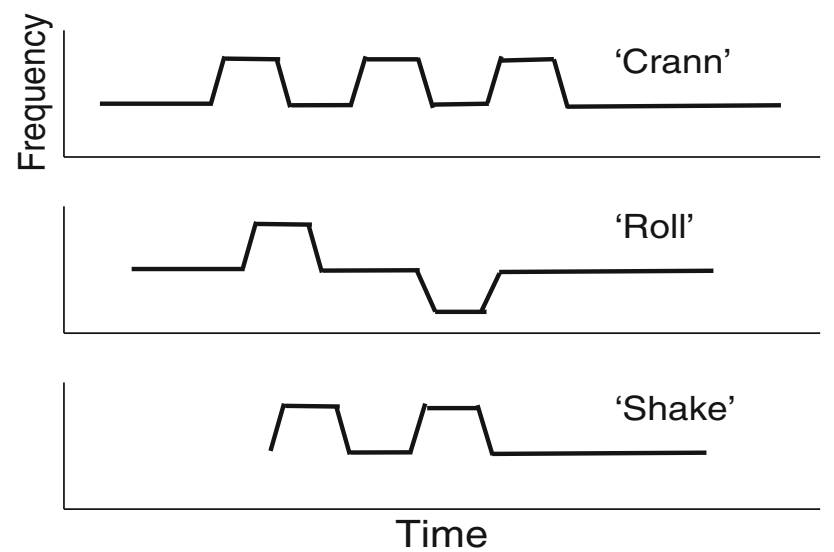

(b)

Fig. 2 A schematic representation of single-note (a) and multi-note (b) ornaments in time-frequency plane

\subsubsection{Multi-note ornaments}

Multi-note ornaments, namely 'roll', 'crann' and 'shake', consist of a particular sequence of an ornamented note and single-note ornaments. 'Roll' consists of the ornamented note, a 'cut', ornamented note, a 'strike' and then returning to the ornamented note. 'Crann' consists of the ornamented note that is cut three times in rapid succession and then returning to the ornamented note. 'Shake' commences with a 'cut', followed by the ornamented note and a second 'cut' and then returning to the ornamented note. A shorter version of 'roll' and 'crann' omit the starting ornamented note. Figure 2 depicts schematic visualisation of single-note and multi-note ornaments in time-frequency plane.

\section{Studies of style in Irish traditional music}

Studies of style in Irish traditional music can often highlight the individuality of selected musicians and an independence of musical style and interpretation that challenges the concept of regional traditions and subjective responses to musical performance. Nevertheless, most studies agree on the ele- ments of musical style and technique and value the creativity of the individual within the wider traditional music community. It is worth nothing also that there is a tendency to focus on musicians from the west of Ireland in these studies [29].

Seán Ó Riada's Our Musical Heritage [54] remains an important reference point in the study of musical style in Irish traditional music, with subsequent contributions from Tomás Ó Canainn [13] and Mícheál Ó Suilleabháin [52] also noteworthy. A number of academic theses have been completed that examine the flute in terms of sociocultural contexts and the development of musical style [17,26,32,59,61]. In addition, a number of flute tutors provide an insight into the transmission of style that of Ó Gráda being particularly relevant in the context of the source material used in this study $[22,38,45,46,50,58]$.

In his study of melody in Irish traditional music, ethnomusicologist James Cowdery [16] asserts that 'the idea of melodic analysis of folk music has received little attention' and endeavours to present 'a comparative study of various interpretations of one tune.' While of merit, his study is limited by the detail given to a single tune, a factor that may be addressed through the development of a digital library that allows analysis of a range of recordings based on a set of researchers' questions.

Studies of individual musicians' styles in Irish traditional music have become more prevalent in recent years with varying degrees of analysis of the approaches and techniques used. Notable examples include Pat Mitchell's details transcriptions of The Dance Music of Séamus Ennis [47] and David Lyth's transcriptions of recordings of various fiddle players with a focus on bowing patterns [41,42].

\section{Music recordings collection}

While Irish traditional music is often defined as a 'solo tradition', the development of a commercial recording industry in the USA at the start of the twentieth century influenced the introduction of accompaniment instruments, primarily piano and guitar. Dillane [18, p. 541] suggests that this was to make the recordings more accessible to a wider audience. From these early recordings to the present day, it is unusual to find commercial recordings of single instruments. Indeed, as noted in [28], it is unusual to find a commercial recording of a 'solo artist' in Irish traditional music today that does not, in fact, feature an ensemble of musicians. Despite these trends, the importance of the solo performer in the mindset and discourse in Irish traditional music has not diminished. Central to this is the creativity that each musician brings to the performance of a tune [48,54]. 


\subsection{Selected flute players and geographical contexts}

The musicians chosen for inclusion in this project represent a wide spread of geographical areas born between 1925 and 1974. At the outset of this project, four flute players were identified as a starting point for the study of style in Irish traditional music: John McKenna, Séamus Tansey, Matt Molloy and Harry Bradley. Additional flute players have also been added including Josie McDermott, Michael Tubridy, Catherine McEvoy, Conal Ó Gráda and John Wynne. The selection of recordings spans from 1921 to 2014 and include recordings made in both Ireland and the USA. The influence of some of the older recordings on the younger generation is widely noted in the sleeve notes and various articles quoting the younger musicians (see e.g. [50]). Despite trends of globalisation, international popularity and technological developments that have changed how music is shared and consumed, in many instances, Irish traditional music retains a sense of local and regional identities that are, in some instances, related to musical styles [30]. While Keegan has chronicled the difficulties in developing a definitive treatise on Irish traditional flute styles [33], the diversity of styles within the tradition remains part of the richness of the soundscape of Irish traditional music. The development of a discourse on musical style in Irish traditional music and the relationship between styles and regional traditions owes much to Seán Ó Riada's seminal 1962 radio series Our Musical Heritage [54]. Included in this study are two of the flute players, Michael Tubridy and Séamus Tansey, who featured in the series. The role and influence of North Connacht flute players on flute styles in Irish traditional music is also evident in a critical consideration of the musicians chosen for inclusion in the digital library.

Clare is often considered a core place in Irish musical traditions. Located on the west coast of Ireland (see Fig. 3), its reputation in the context of Irish traditional music has been widely written about, see for example [25,51]. Michael Tubridy was born in Kilrush in Co. Clare into a musical household in 1935 [60, p. 696-697] and active in the Dublin music scene from the 1960s. Describing Tubridy as 'a perfect example of the Clare style', Ó Riada describes the Clare style as 'a rolling ornamented style, and this combined with the regular phrasing and discreet rhythm, gives it a level, even character' [54].

Many early recordings of Irish traditional music were made in the USA. Leitrim-born John McKenna (1880-1947) was the most prominent flute player to record in America in the early years of commercial recording. In all of the forty-four tracks recorded by McKenna, he is accompanied by other musicians. ${ }^{3}$ For the purposes of the archive, tracks

\footnotetext{
3 A complete collection of his recordings, The Buck from the Mountain, was released in July 2014.
}

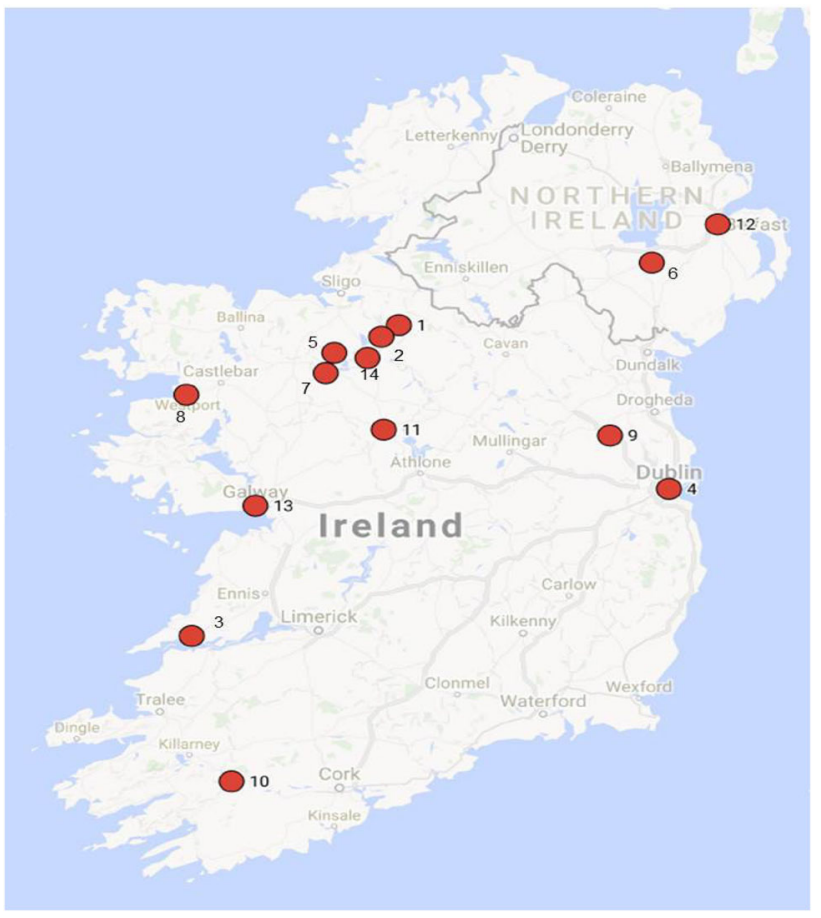

Fig. 3 Geographical location of notable players in Irish traditional music. 1. Tarmon, Co. Leitrim-John McKenna's birthplace; 2. Josie McDermott; 3. Kilrush, Co. Clare-Michael Tubridy; 4. Dublin citymeeting point for many musicians and residence for a time for Tubridy and Molloy; 5. Gorteen, Co. Sligo - Séamus Tansey birthplace; 6 . Craigavon, Co. Armagh-Séamus Tansey residence; 7. Ballaghaderreen, Co. Roscommon-Matt Molloy birthplace; 8. Westport, Co. Mayo-Matt Molloy's pub; 9. Meath-Catherine McEvoy residence; 10. Cúil Aodha, Co. Cork-Conal Ó Gráda; 11. Roscommon townJohn Wynne residence, John Kelly; 12. Belfast, Co. Antrim-Harry Bradley birthplace; 13. Galway, Co. Galway-Harry Bradley residence; 14. Bernard Flatherty

that feature just McKenna and a piano accompanist (who is merely playing or 'vamping' chords) have been selected for future inclusion. Bradshaw notes 'He recorded many polkas, particularly on his duet recordings, and he is renowned for the breathy, rhythmic style of north-east Connacht' [60, p. 442]. A recent compilation of McKenna's recordings [21] includes forewords by Matt Molloy and Conal Ó Gráda, both of whom provide source material for this study and de Barra notes his influence on Tansey, Molloy, Ó Gráda and Bradley in his study of Irish traditional flute playing [17].

Flute playing in Irish traditional music is often associated with the North Connacht region, which includes counties Sligo, Roscommon and Leitrim. Sligo achieved much attention in the early decades of the twentieth century, due in no small part to the success of fiddle players who emigrated from the area to America and became part of the recording industry there. Chief among these were Michael Coleman (18911945), Paddy Killoran (1904-1974) and James Morrison (1893-1947), who played in distinctive but related, highly ornamented styles. Ó Riada suggested that the fiddle and 
flute styles of Sligo were related, although the flute playing was less ornamented, highlighting Peter Horan (1926-2010) as a flute player of note [54]. We include two Sligo born musicians. Josie McDermott (1925-1992) was born in Co. Sligo near the Roscommon border and played a wide range of music and sang, drawing on influences from the popular music of the time. Séamus Tansey was born at Gurteen, Co. Sligo to a musical family in 1943 [60, p. 676-677]. Starting on the tin whistle, Tansey learned informally from local musicians before moving to County Armagh. ${ }^{4}$

Matt Molloy (b. 1947), Catherine McEvoy (b. 1956) and John Wynne (b. 1970) ${ }^{6}$ all have roots in Roscommon and are influenced by the North Connacht tradition of flute playing. Wynne notes that the use of the flute in the region 'likely descends from the nineteenth century prevalence of marching band practices in Connacht' [60, p. 581]. Molloy was born at Ballaghdereen, Co. Roscommon [60, p. 458] and influenced locally by whistle player Jim Donoghue, later moving to Dublin where he performed with a range of notable musicians. Larsen [38] describes Molloy's approach to ornamentation as being 'very dense and dramatic, it is also judicious, perfectly complimenting his long, smooth phrasing... [and has] intense forward motion'.

Cork is the largest county in Ireland with both rural and urban scenes. Cork Pipers' Club, revived in 1963, has had a significant influence on the transmission of music in the area and developed links to Tralibane in West Cork, home of collector and flute player Captain Francis O'Neill [60, p. 167-168]. Cúil Aodha home of Conal Ó Gráda is located in the Gaeltacht. Ó Gráda was born at Ballincollig, Co. Cork in 1961, and his early influences include Mícheál Ó Riabhaigh of the Cork Pipers' Club [60, p. 515]. He was later mentored by Clare flute player Séamus MacMathúna and achieved success in competitions. He is now based in Cúil Aodha, a Gaeltacht region in County Cork. In Companion to Irish Traditional Music [60], fellow flute player Hammy Hamilton notes that Ó Gráda's style is 'unmistakable', described as 'aggressive', 'driving' and 'rhythmic' [60, p. 515]. His repertoire and style includes influences from the Sliabh Luachra region, noted for its repertoire of slides and polkas. His use of glottal stopping for articulation is noteworthy. ${ }^{7}$ Other flute players including flute maker Hammy Hamilton from Belfast also reside there. Ó Gráda and Hamilton together founded Crinniú na bhFlúit ('the flute meeting') in 2006, providing

\footnotetext{
${ }^{4}$ Recordings include Séamus Tansey and Eddie Corcoran (1970), Best of Séamus Tansey (1971), King of the Concert Flute (1976), Reels and Jigs (1980) and Easter Snow (1997).

5 Her solo albums are Catherine McEvoy (1996) and The Home Ruler (2008).

${ }^{6}$ His solo albums are With Every Breath (2000) and Ar nós na gaoithe (2009).

7 Recordings include The Ships are Sailing (1978), The Eavesdropper (1981), The Top of Coom (1990) and Cnoc Buí (2008).
}

spaces for instrumental classes and discussion relating to the flute in Irish traditional music. While Irish traditional music is often associated with rural areas, Dublin and Galway city are significant spaces in Irish traditional music. Both urban areas provide many venues and session spaces. Dublin drew many rural migrants in search of employment in the mid-twentieth century and provided the incubation space for groups and bands to develop [27]. These cities attract large number of tourists whose interest and patronage of Irish traditional music contributes to the vitality of the tradition and related spaces, particularly public houses. Belfast-born Harry Bradley (b. 1974) was initially influenced by popular Irish groups such as Planxty and the Bothy Band and has spent time living in Cork, Dublin and Galway. ${ }^{8} \mathrm{He}$ is also influenced by recordings of Irish traditional music from the 1920s and 1930s. Speaking about his musical style:

I suppose it's a rhythmic style defined by laying down accented rhythms with pulses in the breathing [...] Also, it was always a thing in Belfast to play with a good tone and get a big sound out of the flute... there might have been a dozen flutes in some of the Belfast sessions, so we had to be able to hear ourselves. [57]

Other Belfast flute players include Noel Lenihan, Michael Clarkson, Sam Murray and Brendan O'Hare leading to some observers to propose a 'Belfast style' of flute playing.

We also include recordings of some flute tutors developing an awareness of how style is represented. One example of this is Grey Larsen (b. 1955), a well-known performer, flute maker and author of The Essential Guide to Flute and Tin Whistle [17]. Growing up in Cincinnati, Ohio, USA, he studied early music at two conservatories while, learning Irish traditional music from elder Irish immigrant musicians, most notably Co. Galway melodeon player Michael J. Kennedy (1900-1978), Co. Sligo flute player Tom Byrne (1920-2001) and Co. Leitrim fiddler Tom McCaffrey (19162006) [39]. The CDs accompanying his book include a range of traditional tunes as well as exercises showing a deep understanding of ornamentation and teaching techniques.

\section{Music corpus and annotations}

This section describes the corpus of music recordings we have collected with the focus on stylistic analysis through ornamentation and their annotations we have performed. The dataset is publicly available through GitHub [5]. We start with an overview of the audio recordings and corpus statistics. Then, we describe the process of manual annotation of the

\footnotetext{
${ }^{8}$ Solo recordings by Harry Bradley include Bad Turns and Horse-shoe Bends (2000), As I Carelessly Did Stray (2002), The Night Rambler's Companion (2006) and The First of May (2014).
} 
Table 1 List of commercially released CDs with the list of tunes used in the corpus

\begin{tabular}{|c|c|c|}
\hline \multicolumn{2}{|l|}{$\mathrm{CD}$} & \multirow[t]{2}{*}{ Tunes used } \\
\hline Player & Title & \\
\hline H. Bradley & The First of May & $\begin{array}{l}\text { Ah Surely, The Hares Paw, Happy to Meet Sorry } \\
\text { to Part, The Flowers of Red Hill, The Gallant } \\
\text { Boys of Tipperaray, The Whinny Hills of } \\
\text { Leitrim, The Dancer at the Fair, Fishers, The } \\
\text { Rakes of Kildare, Mamas Pet }\end{array}$ \\
\hline G. Larsen & $\begin{array}{l}\text { The Essential Guide to Flute and } \\
\text { Tin Whistle }\end{array}$ & $\begin{array}{l}\text { The Lonesome Jig, Study5, Study6, Study11, } \\
\text { Study17, Study22, Tom Billys Jig, The Frost is } \\
\text { All Over, The Humours of Ballyloughlin, The } \\
\text { Rose in the Heather, The Scotsman Over the } \\
\text { Border, A Fig for a Kiss, Hardiman the Fiddler, } \\
\text { The Whinny Hills of Leitrim, Roaring Mary, } \\
\text { The Drunken Landlady, The Lady on the } \\
\text { Island, The Mountain Road, The Shaskeen, The } \\
\text { Maids of Ardagh }\end{array}$ \\
\hline J. McDermott & Darby's Farewell & $\begin{array}{l}\text { The Kerry Man, The Pigeon on the Gate, The } \\
\text { Bush Hornpipe, Dunphys Hornpipe, Dominics } \\
\text { Farewell to Cashel, Trip to the Cottage }\end{array}$ \\
\hline C. McEvoy & $\begin{array}{l}\text { Traditional Flute Playing in the } \\
\text { Sligo-Roscommon Style }\end{array}$ & McGivney's Fancy \\
\hline \multirow[t]{3}{*}{ M. Molloy } & Heathery Breeze & $\begin{array}{l}\text { The Bush in Bloom, Drowsy Maggie, The Hare } \\
\text { in the Heather }\end{array}$ \\
\hline & Shadows on Stone & The Crib of Perches, The Masons Apron \\
\hline & M. Molloy & The Gold Ring, The Humours of Ballyloughlin \\
\hline C. O’ Grada & Cnoc Bui & $\begin{array}{l}\text { Mickey Duggans Polka No1, Mickey Duggans } \\
\text { Polka No2, Cus Teahans, Jim Donoghues, The } \\
\text { Edenderry Reel, The Church Street Polka, The } \\
\text { Happy Polka, The Fishermans Lilt, The Caucus } \\
\text { Reel, Muing Phliuch Jig, Green Mountain, The } \\
\text { Rookery, Maurice O Keeffes, John Walshes, } \\
\text { The Old Copperplate, The Old Bush }\end{array}$ \\
\hline S. Tansey & Field Recordings & $\begin{array}{l}\text { The Flax in Bloom, The Blackberry Blossom, } \\
\text { The Maid Behind the Bar, Cornel Fraizer }\end{array}$ \\
\hline M. Tubridy & The Eagle's Whistle & $\begin{array}{l}\text { The Humours of Derrykissanne, The Campbells } \\
\text { are Coming, The Hawthorn, The Ashplant, For } \\
\text { the Sake of Old Decency }\end{array}$ \\
\hline Various & Flute Players of Roscommon Vol 1 & $\begin{array}{l}\text { J. Wynne: The Girl in the Big House, The } \\
\text { Killavil Jig, The Maid on the Green; } \\
\text { C. McEvoy: Crehans Kitchen, The Sand Mount, } \\
\text { Mulvihills; } \\
\text { B. Flaherty: Down the Broom, The Gatehouse } \\
\text { Maid; } \\
\text { J. Kelly: Gerrys Beaver Hat, Adam and Eve }\end{array}$ \\
\hline
\end{tabular}

audio and highlight the lessons learned and explain the annotation information and other metadata about the tunes and artists. Finally, we provide some statistical analysis of notes and ornamentation in the corpus that inform some aspects of playing style.

\subsection{Audio recordings}

The corpus of audio recordings currently consists of 79 tunes from 11 players, who are introduced in Sect. 4.1. The tunes come from 12 commercially released CDs. Table 1 gives the list of the CDs, indicating the players and tunes selected. The tunes were specifically selected with the aim of having audio with no (or minimal) accompaniment. The original recordings are in uncompressed wav format, stereo, sampled at $44.1 \mathrm{kHz}$ with 16 bits per sample. These are converted into monophonic signal, by summing the signal in both channels. For each of the 79 tunes, the first repetition ${ }^{9}$ in the tune (see Sect. 2.1) was extracted from the audio and stored. In

\footnotetext{
${ }^{9}$ Except for two tunes for which the second repetition was used.
} 
Table 2 Number of tune types used for each player

\begin{tabular}{|c|c|c|c|c|c|c|c|c|c|c|c|c|}
\hline \multirow[t]{2}{*}{ Tune type } & \multicolumn{11}{|c|}{ Player name } & \multirow[t]{2}{*}{ Total } \\
\hline & Bradley & Flaherty & Kelly & Larsen & McDermott & McEvoy & Molloy & Ó Gráda & Tansey & Tubridy & Wynne & \\
\hline Jigs & 4 & - & 1 & 11 & 2 & - & 2 & 1 & - & 3 & 3 & 27 \\
\hline Reels & 4 & 2 & - & 8 & 2 & 4 & 5 & 9 & 4 & 2 & - & 40 \\
\hline Hornpipes & 2 & - & 1 & - & 2 & - & - & - & - & - & - & 5 \\
\hline Polka & - & - & - & 1 & - & - & - & 6 & - & - & - & 7 \\
\hline Total & 10 & 2 & 2 & 20 & 6 & 4 & 7 & 16 & 4 & 5 & 3 & 79 \\
\hline
\end{tabular}

Table 3 Numbers of the Irish traditional music audio collection for each player

\begin{tabular}{|c|c|c|c|c|c|c|c|}
\hline \multirow[t]{2}{*}{ Player } & \multirow[t]{2}{*}{ Key of flute } & \multirow[t]{2}{*}{ Albums } & \multirow[t]{2}{*}{ Tunes } & \multirow[t]{2}{*}{ Notes } & \multicolumn{2}{|l|}{ Ornaments } & \multirow[t]{2}{*}{ Total duration } \\
\hline & & & & & Single-note & Multi-note & \\
\hline H. Bradley & $\mathrm{F}, \mathrm{Eb}$ & 1 & 10 & 1524 & 218 & 91 & $4 \min 44 s$ \\
\hline B. Flaherty & $\mathrm{D}$ & 1 & 2 & 303 & 30 & 15 & $53 \mathrm{~s}$ \\
\hline J. Kelly & $\mathrm{D}$ & 1 & 2 & 154 & 18 & 12 & $33 \mathrm{~s}$ \\
\hline G. Larsen & $\mathrm{D}$ & 2 & 20 & 2666 & 462 & 182 & $12 \mathrm{~min}$ \\
\hline J. McDermott & $\mathrm{D}$ & 1 & 6 & 1233 & 99 & 57 & $3 \min 48 s$ \\
\hline C. McEvoy & $\mathrm{D}$ & 2 & 4 & 569 & 53 & 28 & $1 \mathrm{~min} 40 \mathrm{~s}$ \\
\hline M. Molloy & $\mathrm{D}, \mathrm{Eb}, \mathrm{Bb}$ & 3 & 7 & 1347 & 152 & 148 & $5 \min 5 s$ \\
\hline C. Ó Gráda & $\mathrm{D}, \mathrm{Eb}$ & 1 & 16 & 2545 & 389 & 117 & $8 \min 4 s$ \\
\hline S. Tansey & $\mathrm{D}$ & 1 & 4 & 472 & 43 & 65 & $1 \min 34 s$ \\
\hline M. Tubridy & $\mathrm{D}$ & 1 & 5 & 717 & 86 & 36 & $2 \min 4 s$ \\
\hline J. Wynne & $\mathrm{D}$ & 1 & 3 & 461 & 50 & 25 & $1 \min 32 \mathrm{~s}$ \\
\hline Total & - & 15 & 79 & 11,991 & 1603 & 776 & $41 \min 57 \mathrm{~s}$ \\
\hline
\end{tabular}

addition to this, we also extracted second/third repetitions from some of the tunes, in total 20. Therefore, there are 99 audio files with annotations in total. All presented analyses in the following sections are based on the set of 79 tunes without the additional repetitions in order to avoid an artificial bias due to the repetitions.

\subsection{Corpus statistics}

Table 2 gives the statistics of the types of tunes played by each player. It can be seen that jigs and reels are the most common tune types shared by most of the players in our collection, while hornpipes and polka are played only by three and two players, respectively.

The total length of annotated audio is over 40 mins, and this contains 11,991 notes, 1603 single-note and 776 of multinote ornaments.

Table 3 gives the statistics for each player, specifically, the key of the flutes used, the number of notes and single- and multi-note ornaments for each player, with the total duration of annotated audio. The flutes played on the recordings include flutes pitched in different keys. The most common is the $D$ flute. However, there are several reasons a player may
Table 4 Keys of flutes played in corpus (D, Eb, F, Bb) and the notes present for each key

\begin{tabular}{lllllllll}
\hline Key of flute & \multicolumn{2}{l}{ Notes present } \\
\hline D flute & $\mathrm{D}$ & $\mathrm{E}$ & $\mathrm{F} \#$ & $\mathrm{G}$ & $\mathrm{A}$ & $\mathrm{B}$ & $\mathrm{C}$ & $\mathrm{C \#}$ \\
Eb flute & $\mathrm{Eb}$ & $\mathrm{F}$ & $\mathrm{G}$ & $\mathrm{Ab}$ & $\mathrm{Bb}$ & $\mathrm{C}$ & $\mathrm{Db}$ & $\mathrm{D}$ \\
F flute & $\mathrm{F}$ & $\mathrm{G}$ & $\mathrm{A}$ & $\mathrm{Bb}$ & $\mathrm{C}$ & $\mathrm{D}$ & $\mathrm{Eb}$ & $\mathrm{E}$ \\
Bb flute & $\mathrm{Bb}$ & $\mathrm{C}$ & $\mathrm{D}$ & $\mathrm{Eb}$ & $\mathrm{F}$ & $\mathrm{G}$ & $\mathrm{Ab}$ & $\mathrm{A}$
\end{tabular}

play a flute in a different key. Within the corpus, both Harry Bradley and Matt Molloy play flutes in $E b, F$ and $B b$. The $E b$ and $F$ flutes are higher pitched than $D$ flute and as such they can provide a brighter sound. Matt Molloy's $B b$ flute is lower in pitch than a concert $D$ flute and will therefore give a more mellow sound.

Table 4 gives the set of notes present for each key of flute present in our corpus. While the 'standard' flute is $D$, a player will refer to any transposing flute as if it is in the key of $D$. The note name is always taken from the finger positions covering the holes, e.g. covering the top three holes on a $D$ flute would result in the note of $G$. A player asked to play a $G$ note while holding an $F$ flute would still cover the top three holes. The actual note produced would be a $B b$. 


\subsection{Manual annotation of the audio data}

The purpose of manual annotation of the audio data was to provide for each tune information on the onset of notes, the pitch of notes and the presence and type of ornamentation. The annotation was performed by an experienced player of Irish traditional flute.

\subsubsection{Annotation process}

The first annotations were performed using Sonic Visualiser tool [14] with the vamp plugins Aubio Pitch Detector and Aubio Note Tracker [12]. The annotation procedure is described in [37]. Attempts were made to use the Aubio Note Tracker to automatically detect the note pitch and onsets, with the aim of using this as a base for making manual annotation. However, the amount of manual corrections required to achieve an accurate annotation made this method very inefficient. We then explored a way of manually drawing the notes based on what was heard in the audio file, together with the support of the Aubio Pitch Detector and a representation of the audio waveform as visual guides for pitch, onset and offset. Although somewhat more efficient, the process of using Sonic Visualiser was time consuming.

The current annotations were performed using the software tool Tony [43], which was specifically designed for manual annotation of note content. This tool was found to provide a more accurate automatic note detection and allowed for the start and end of the note to be manually moved to the correct ground truth positions. Also, the $F_{0}$ tracking, which is performed using the PYIN algorithm [44], did not present as many of the octave doubling issues as were found in Aubio. This has resulted in a faster manual annotation process. When the manual annotation of note pitch and timing was completed, a synthesised audio stream generated from the annotation data was played back without the original audio. This was compared with the recorded track to ensure that the annotated content is a correct representation of the original performance. As a last step, checking the onset times and $F_{0}$ in manual annotations for accidental errors was also performed by employing automatic algorithms for onset detection (e.g. [20]) and $F_{0}$ estimation (e.g. [56]) to identify events which differed significantly from the manual annotations. These events were then checked again manually in the annotations, by also examining their context (i.e. previous and subsequent events), and corrected if needed [2].

Many lessons were learned through the annotation process. The combined use of better tools and more experience allowed the time taken to annotate a typical tune from over three hours to just over an hour. It is ideal for the manual annotations to be performed by an experienced player of the Irish traditional flute. However, it is believed that a person with a general music background and a suitable training may be able

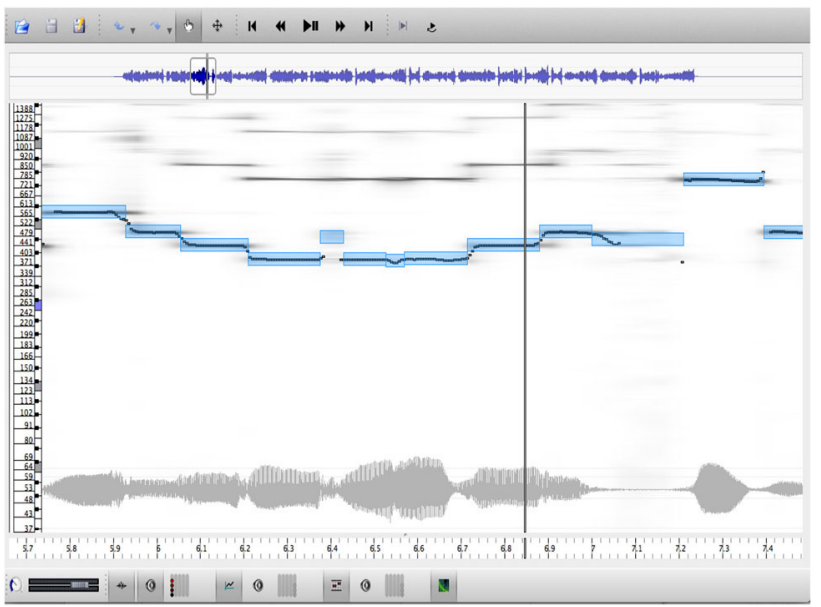

Fig. 4 An example of a screenshot from Tony analysis and annotation software, depicting the waveform (bottom) and spectrogram with indicated manually annotated notes (light blue horizontal blocks). (tune: McGivney's Fancy by Catherine McEvoy)

to provide annotations of the required standard. The training would need to provide a good knowledge of the capabilities of the flute, Irish traditional flute music and ornamentation as well as contextual understanding of the music being annotated. An example of the latter is when a player attempts a five-note ornament like a long roll, but does not correctly play the strike-depending on the severity of the mistake there may be a slight pitch deviation or no deviation at all.

\subsubsection{Annotation example}

Figure 4 shows a screenshot of manual annotation in Tony. The notes are part of McGivney's Fancy, a reel played by the celebrated Roscommon flute player Catherine McEvoy. The bottom of the screen shows the waveform of the source audio file and the light blue horizontal blocks in the centre of the screen depict the note onset and offset with frequencies taken from the piano roll on the left-hand side. The darker line running through the centre of each block is the $F_{0}$ frequency estimates using PYIN. In this example, the $F_{0}$ is accurate apart from the fifth note, a 'cut' which was not detected but then manually corrected.

The corresponding annotation data can be seen in Table 5 . The annotation indicates segmentation of the audio signal, where each segment includes the following information: time of onset, time of offset, type of segment, note identity (if applicable) and note frequency (if applicable). The type of a segment may be one of the following: note, 16th note, one of the types of single-note or multi-note ornaments and breath. During post processing, the note identities are determined based on the frequency and breaths are annotated with a frequency of $0 \mathrm{~Hz}$. 
Table 5 An example of the manual annotation of an excerpt from the tune McGivney's Fancy played by Catherine McEvoy

\begin{tabular}{lllll}
\hline Onset $(\mathrm{s})$ & Offset $(\mathrm{s})$ & Type of segment & Note identity & Note frequency (Hz) \\
\hline 5.7339 & 5.9283 & Note & D5 & 586.6 \\
5.9283 & 6.0546 & Note & B4 & 494.9 \\
6.0546 & 6.2099 & Note & A4 & 440.6 \\
6.2099 & 6.3753 & lngRoll_nt & G4 & 391.2 \\
6.3753 & 6.4290 & lngRoll_ct & B4 & 473.0 \\
6.4290 & 6.5263 & lngRoll_nt & G4 & 391.9 \\
6.5263 & 6.5683 & lngRoll_str & G4 & 385.7 \\
6.5683 & 6.7135 & lngRoll_nt & G4 & 391.9 \\
6.7135 & 6.8789 & Note & A4 & 441.5 \\
6.8789 & 6.9994 & Note & B4 & 493.9 \\
6.9994 & 7.2098 & Breath & BR & 0 \\
7.2098 & 7.3941 & Note & G5 & 773.9 \\
7.3941 & 7.5450 & Note & B4 & 492.7 \\
\hline
\end{tabular}

\subsection{Statistical analysis of notes and ornamentation}

This section provides an initial quantitative response to the ethnomusicological questions that are usually addressed in a qualitative manner and which are sometimes undermined by perceived subjectivity. This is performed through a variety of statistical analysis of the audio data obtained based on the manual annotation. Specifically, we present analysis of duration of notes and ornaments, quantity of ornamentation used by various players and analysis of note sequences. This information provides some pointers towards the study of style as well as it would be useful for development of an automatic system to analyse the audio, e.g. $[24,36]$. For instance, the durations of notes and ornaments can be exploited in designing a suitable temporal filtering operations for detection of onsets and ornaments and the knowledge of note sequences in an automatic transcription system as a prior probability of the note following the current note.

\subsubsection{Durations}

While musical notation often notates notes of even duration, it is recognised that, in many musical traditions, different weightings are given to notes of the same written value and ornamentation is particularly challenging to notate. As such, in this section, we examine the durations of singlenote ornaments and of notes (excluding those taking part in ornaments). The obtained histograms are depicted in Fig. 5. These indicate that the duration of ornaments is considerably lower than that of notes. The mode of the duration distribution of single-note ornaments is at $45 \mathrm{~ms}$, while it is $130 \mathrm{~ms}$ for notes. In $90 \%$ of cases, the duration of single-note ornaments is between $30 \mathrm{~ms}$ to $70 \mathrm{~ms}$ and of notes between $80 \mathrm{~ms}$ to $220 \mathrm{~ms}$.

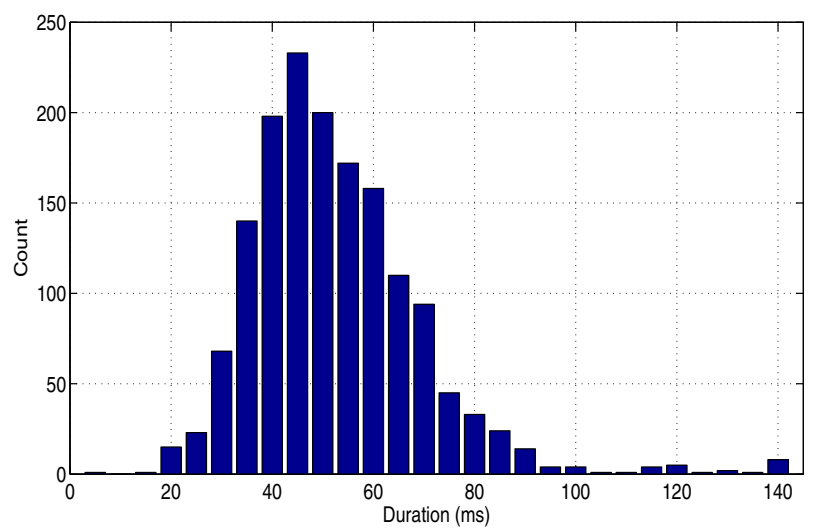

(a)

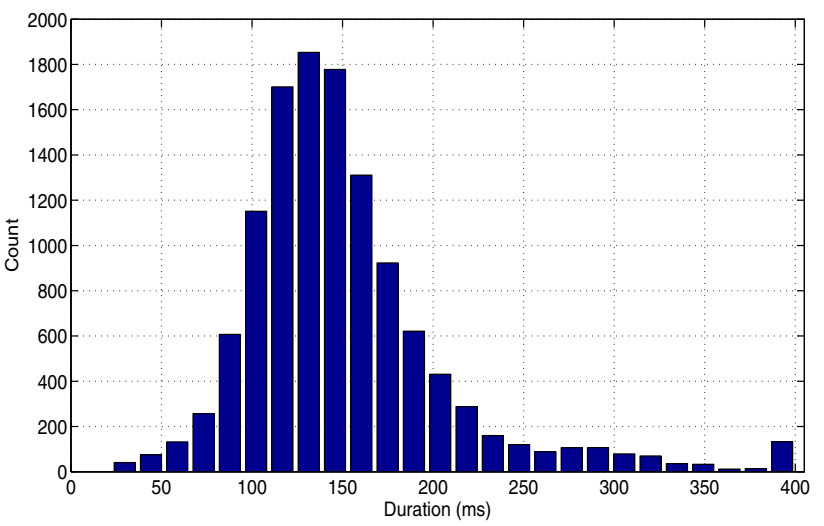

(b)

Fig. 5 The distribution of the duration of single-note ornaments (a) and notes (b) in our recordings

We also analysed the note duration separately for each type of tune. We observed that notes in reels were by average around $20 \mathrm{~ms}$ shorter than those of jigs. This is in agreement with the fact that reels are usually played at a faster tempo 


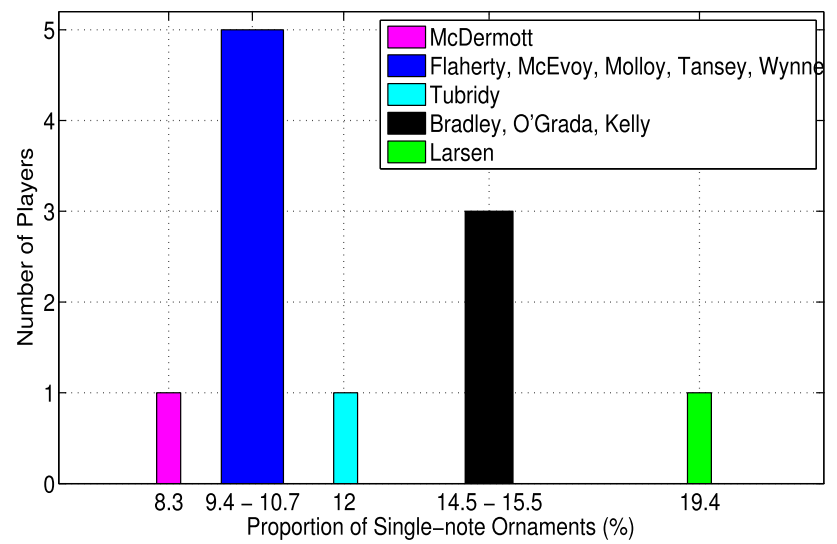

(a)

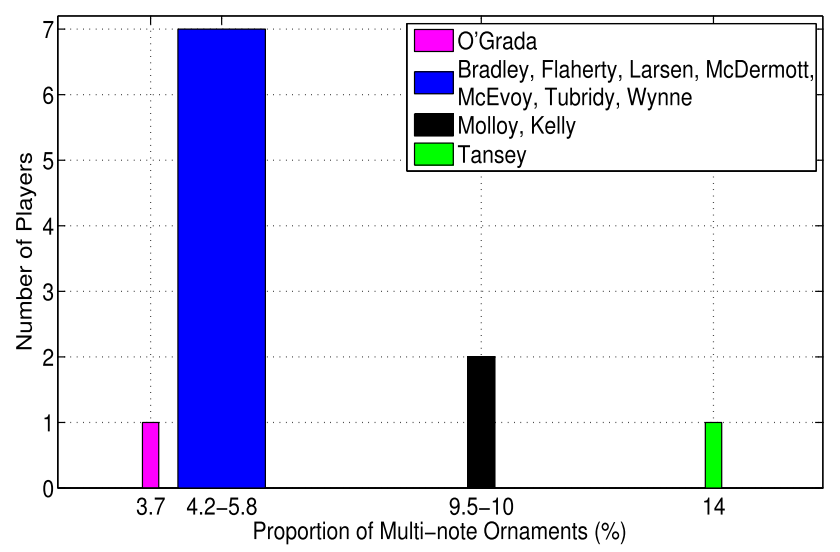

(b)

Fig. 6 The proportion of number of ornaments to the number of notes played for each player: single-note ornaments (a) and multi-note ornaments (b)

than jigs. Breathnach gives suggested tempos for tunes in Irish traditional music, but these can vary based on the individual choices made by musicians and, in some instances, regional styles.

\subsubsection{Quantity and type of ornamentation}

Descriptions of musical styles in Irish traditional music often focus on the use and variety of ornamentation in a performance. To analyse these on our corpus, we calculated the proportion of the number of single-note and multi-note ornaments to the number of notes played. For each player, the average over all tunes of the player in the corpus was calculated. Results are depicted in histogram-like visualisations in Fig. 6. In these figures (and also in figures in Sect. 5.4.3), data are in a way clustered along the $x$-axis - the width of the bars indicates the range on the $x$-axis, while the height indicates the number of players falling within the range. The median of the usage of single-note ornaments is $10.7 \%$, and most players fall around this region, corresponding to the blue (tallest) bar. The player with least amount of single-note ornamentation is McDermott. The most number of singlenote ornaments is used by Larsen, but this may be due to the fact that his recordings are tutorial exercises for learning Irish traditional flute playing. Among the other players, Bradley, Ó Gráda and Kelly (though the last might be affected by small amount of data in our corpus) use around $15 \%$ of ornaments, which is around 50\% higher than most of the other players. While most of the single-note ornamentation is 'cut' ornaments, it is notable that Bradley and Ó Gráda use the most number of 'strike' ornaments, more than twice the median of all players.

Analysing the usage of multi-note ornaments, we can see that the usage is around $5 \%$ by most of the players. Noticeable is Ó Gráda with lowest usage. This may be related to his style and also repertoire, with performers less likely to use rolls in polkas. When 6 polkas are excluded from the counts, his average usage is with $5.4 \%$ and he falls into the main blue bar with most players. On the contrary, Tansey, with over $14 \%$, is far the most prominent for using multi-note ornaments. He is recognised as a highly ornamented player from within a style that is celebrated for its ornamentation. A high usage, just under $10 \%$, is also seen in tunes by Molloy and Kelly. The high usage of multi-note ornaments by Molloy was noted by Larsen [38], as mentioned earlier in Sect. 4.1. Among the types of multi-note ornaments, 'roll' was the most widely used. Nearly all of the multi-note ornaments used by Tansey are 'roll.' 'Shake' is used considerably in nearly all tunes by Bradley and McDermott with 3.8\% and 3.6\%, respectivelythis is their most used multi-note ornament, being 1.9 and 2.8 times higher usage than 'roll', respectively. Other players use 'shake' from 0 to $1.5 \%$. 'Crann' is barely used, only in few tunes among all the players. Looking at the key played for the players with most 'roll', the tunes by Tansey are in $G$ and in D and those by Molloy are in G, in D and E. Interestingly, these would be considered as easy keys for ornamentation due to the accessibility of notes required for the ornament. These are also the most popular key signatures within the wider repertoire on most instruments, although A major is popular for fiddle and related instruments.

\subsubsection{Quantity of breaths}

Phrasing is identified as another key component of musical style in flute playing. On the flute, each phrase in performance is marked by a breath. Unlike in classical music, where the composer may indicate a phrasing, the length of phrases in Irish traditional music is at the discretion of the performer, allowing for accepted norms within the tradition. The analysis of phrasing related to the number of breaths taken by a performer during a tune is depicted in Fig. 7. It is evident that most of the flute players sampled take approximately 2 to 3 


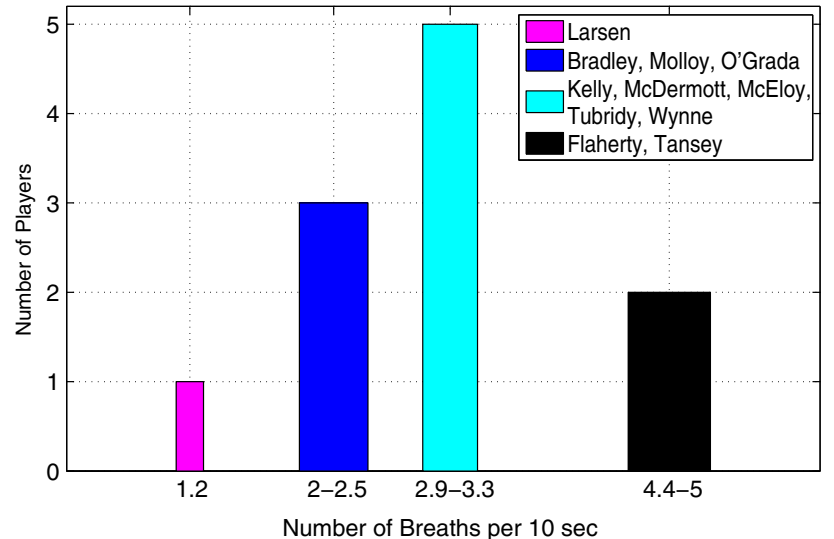

Fig. 7 The number of breaths per $10 \mathrm{~s}$ of playing

breaths per $10 \mathrm{~s}$ of playing. Flaherty and Tansey take considerably more frequent breaths, i.e. they play with a greater number of phrases. Taking more breaths or 'breaking the phrases' results in a more energetic, 'bouncier' performance, favoured by some but contrasting with smoother, legato styles favoured by some listeners. The very little usage of breathing by Larsen may be due to a controlled tutoring-like tune playing.

\subsubsection{Music language model}

This section relates more to understanding the musical distinctiveness of the Irish tradition. Ethnomusicologists recognise the use of particular scales and musical patterns in some traditions and although the cantometrics project pioneered by Alan Lomax [40] is often criticised, such patterns raise important musicological questions about the structures and creation of music.

We examined the structure of the tunes in terms of statistics of notes and note sequences. This is referred to as music language model. Specifically, we calculated so-called unigram and bigram language model probabilities. The unigram model refers to the probabilities of notes happening in data. The bigram model expresses the probability of a note given the identity of the previous note. The obtained unigram and bigram probability distributions are depicted in Fig. 8a, b, respectively. It can be seen from the unigram language model that the note $A 4$ is the most common, while notes $C 6$ and $C \# 6$ appear rarely in the tunes. ${ }^{10}$ In the bigram model, the row indicates the previous note and the column the current note, i.e. the element at row $i$ and column $j$ denotes the probability $P\left(n_{j} \mid n_{i}\right)$. The bigram probabilities whose value was 0 were floored to the value of -3 in the $\log$-scale. It can be seen that there is a considerable amount of note pairs

\footnotetext{
$\overline{10}$ These notes are rarely written and can sound very unstable. The 'usual' highest note is $B 5$.
}

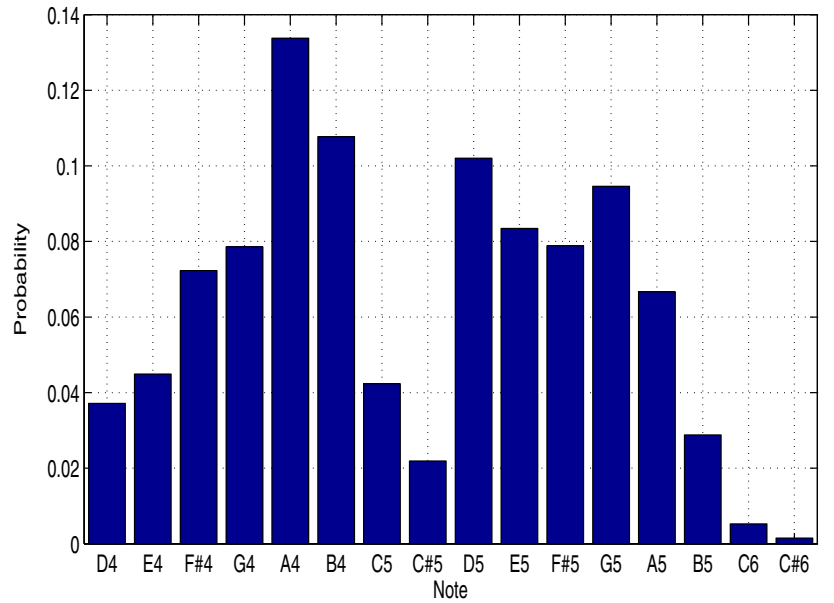

(a)

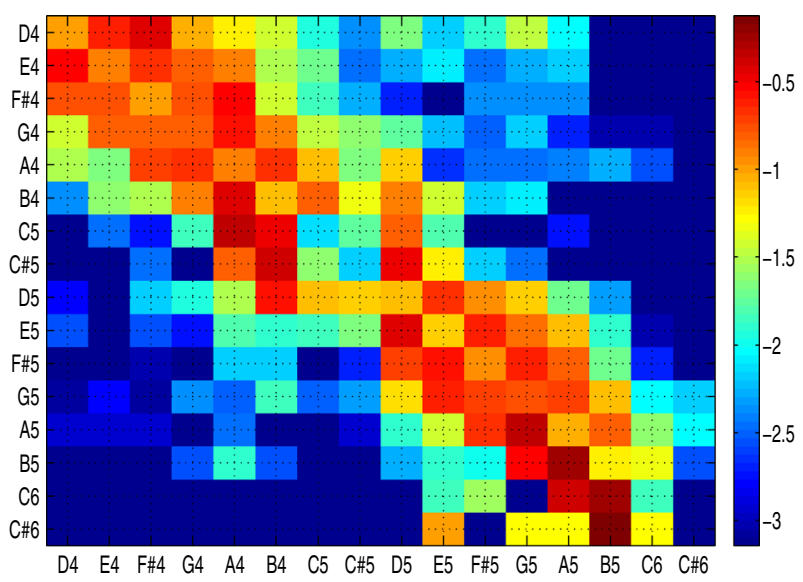

(b)

Fig. 8 Unigram (a) and Bigram music language model calculated across all tunes played by key D flute, depicted in $\log 10$ scale (b)

which never happened. In general, the most likely note pairs are notes next to each other. Note that neighbouring notes are the most likely notes used in ornamentation, notably in strikes and rolls.

\subsection{Automatic annotation}

Along with the manual annotation, we have conducted research on methods for music information retrieval, specifically to detect onsets and ornaments and estimate note frequency in a view to obtain annotation of the tunes automatically. In this paper, we present the results of onset detection obtained using two conventional onset detection algorithms, which is to serve as a baseline for future research in this area. Both methods exploit the change of the signal amplitude over time, with processing performed in the temporal and spectral domain. The description of these methods, which we also 
Table 6 Results of onset detection obtained using conventional onset detection methods

\begin{tabular}{llll}
\hline Algorithm for onset detection & \multicolumn{3}{l}{ Evaluation performance $(\%)$} \\
\cline { 2 - 4 } & Precision & Recall & $F$-measure \\
\hline Sig-energy—-spectral & 83.0 & 79.8 & 81.4 \\
Sig-energy_temporal & 84.6 & 79.1 & 81.8 \\
\hline
\end{tabular}

used in our previous onset detection research, is provided in [36].

We performed extensive evaluations with different parameter values for each of these conventional onset detection methods. The best achieved performance for each of the methods is presented in Table 6 . It can be seen that they both perform similarly, achieving the $F$-measure of over $81 \%$.

\section{Conclusion and future directions}

This paper presented the curation and annotation of a research corpus of traditional Irish flute recordings to facilitate stylistic analysis. We started with an overview of the structure of Irish traditional music, types of tunes and ornamentation. This was followed with presentation of studies of style in Irish traditional music and with information about the players included in our collection and geographical context. The main part of the paper was then devoted to the description of the collection of recordings and metadata content in the library and several statistical analysis of the corpus providing initial insights into stylistic analysis of individual players. We also presented the performance of a baseline of a conventional automatic system for detection of onsets.

Although the presented digital library is not large, it presents a valuable content to musicians and researchers in the musicology as well as technology community. For instance, even the current size of the library, containing over 15,000 annotated note onsets, is well sufficient for developing automatic systems for note onset detection, note transcription and to some extent ornament detection. We aimed to use in this library only unaccompanied flute recordings. This is advantageous in regard to the development of automatic systems to analyse the audio signal. Data can be analysed without the need of a pre-processing phases such as source separation that could affect the timbre of the flute featured in the performance. However, to locate unaccompanied recordings presented a considerable obstacle as most flute players will typically assemble a number of musicians (or at least one accompanist in the form of a piano or guitar player) for a recording session to provide rhythmic and chordal backing.

The presented information on the annotation process of the audio signal can be adopted by others in developing future libraries. The inclusion of accompanying recordings would be interesting for future expansion of the library, but this would make also the annotation process more complex. A collection of such libraries could then be used for thorough analysis of various aspects of stylistic interpretations.

The presented digital library is aimed at users in both the musicology and technology communities. In context of technology users, there is in general a huge interest to have annotated data in order to develop a variety of music information retrieval (MIR) systems, e.g. participants of International Society for Music Information Retrieval conference. We have used parts of the library in our recent research on developing methods for an automatic detection of note onsets and ornaments and note transcription $[24,36]$. There are a number of ways the library would be useful for musicology users. We expect the presented digital library content to be useful to others working in this domain for developing an awareness of how style is represented and of the creative processes in Irish traditional music as well as preserving cultural heritage. Irish traditional music and culture are strongly related. The dissemination of style within Irish traditional music is of interest to a wider set of ethnomusicologists and social science researchers as it can be used as a way to test the inherent strength of culture in a particular area. For ethnomusicologists, the digital library and related research presents new opportunities for methodological development that can reinforce other data collection or inspire further ethnographic research that can provide context and/or further source material for future research and inclusion in the digital library. Another potential usage is in the context of archives whereby information can be generated to help catalogue and organise examples for future research. The resource could also be adapted for use in the transmission process, enabling students to identify stylistics aspects in their playing as well as in the playing of others.

Open Access This article is distributed under the terms of the Creative Commons Attribution 4.0 International License (http://creativecomm ons.org/licenses/by/4.0/), which permits unrestricted use, distribution, and reproduction in any medium, provided you give appropriate credit to the original author(s) and the source, provide a link to the Creative Commons license, and indicate if changes were made.

\section{References}

1. AHRC. Transforming musicology. http://www.transformingmusicology.org/ (2014). Accessed 20 Jan 2016

2. Ali-MacLachlan, I.: Computational analysis of style in Irish flute playing. Ph.D. Thesis (Unpublished), Birmingham City University, UK (2018)

3. Ali-MacLachlan, I., Köküer, M., Athwal, C., Jančovič, P.: Towards the identification of Irish traditional flute players from commercial recordings. In: Proceedings of the International Workshop on Folk Music Analysis (FMA), Paris, France, pp. 13-17 (2015) 
4. Ali-MacLachlan, I., Köküer, M., Jančovič, P., Williams, I., Athwal, C.: Quantifying timbral variations in traditional Irish flute playing. In: Proceedings of the International Workshop on Folk Music Analysis (FMA), Amsterdam, Netherlands (2013)

5. Ali-MacLachlan, I., Köküer, M., Kearney, D., Jančovič, P.: Dataset for "Characterising stylistic interpretations through automated analysis of ornamentation in Irish traditional music recordings'. https://github.com/izzymaclachlan/datasets/ tree/master/GT-ITM-Flute-99. Accessed 01 Dec 2018

6. Breathnach, B.: Ceol Rince na hÉireann 1. An Gúm, Dublin (1963)

7. Breathnach, B.: Folk Music and Dances of Ireland. Ossian, London (1971/1996)

8. Breathnach, B.: Ceol Rince na hÉireann 2. An Gúm, Dublin (1976)

9. Breathnach, B.: Ceol Rince na hÉireann 3. An Gúm, Dublin (1985)

10. Breathnach, B.: Folk Music and Dances of Ireland. Ossian, London (1996)

11. Brennan, H.: The Story of Irish Dance. Roberts Rinehart, Maryland (2001)

12. Brossier, P.M.: Automatic annotation of musical audio for interactive applications. Ph.D. Thesis, Queen Mary, University of London (2006)

13. Canainn, T.O.: Traditional Music in Ireland. Ossian Publications Ltd, Cork (1978)

14. Cannam, C., Landone, C., Sandler, M.: Sonic visualiser: an open source application for viewing, analysing, and annotating music audio files. In: International Conference on ACM Multimedia, Firenze, Italy, pp. 1467-1468 (2010)

15. Cooper, P.: The Complete Irish Fiddle Player. Mel Bay Publications, St. Louis (2010)

16. Cowdery, J.R.: The Melodic Tradition of Ireland. Kent State University Press, Kent (1990)

17. de Barra, E.: A critical analysis of traditional Irish flute playing. M.A. Dissertation, Dundalk Institute of Technology (2015)

18. Dillane, A.: 'Piano' in Companion to Irish Traditional Music. Cork University Press, Cork (2011)

19. Duggan, B.: Machine annotation of traditional Irish dance music. Ph.D. Thesis, Dublin Institute of Technology, School of Computing, Dublin (2009)

20. Eyben, F., Böck, S., Schuller, B., Graves, A.: Universal onset detection with bidirectional long short-term memory neural networks. In: Proceedings of the 11th International Society for Music Information Retrieval Conference (ISMIR), pp. 589-594

21. Gilrane, S.: The Buck from the Mountain: The Music and Life of John McKenna. John McKenna Society, Leitrim (2014)

22. Hamilton, S.: The Irish Flute Player's Handbook: A Comprehensive Guide to the Traditional Flute in Ireland. Breac Publications, Coolea $(1990 / 2008)$

23. Hast, D.E., Scott, S.: Music in Ireland: Experiencing Music. Expressing Culture. Oxford University Press, Oxford (2004)

24. Jančovič, P., Köküer, M., Baptiste, W.: Automatic transcription of ornamented Irish traditional flute music using hidden Markov models. In: Proceedings of the 16th International Society for Music Information Retrieval Conference (ISMIR), Malaga, Spain, pp. 756-762 (2015)

25. Kaul, A.R.: Turning the Tune: Traditional Music, Tourism, and Social Change in an Irish Village. Berghahn Books, New York (2013)

26. Kavanagh, N.: Regionalism in pre-revival Irish traditional flute performing styles: fact or fiction? M.A. Thesis, Waterford Institute of Technology (2001)

27. Kearney, D.: (Re)locating Irish Traditional Music: Urbanising Rural Traditions (2007)

28. Kearney, D.: The solo ensemble: trends in Irish traditional music recordings by solo artists. In: International Council for Traditional Music Conference, Limerick, Ireland (2010)
29. Kearney, D.: Towards a regional understanding of Irish traditional music. Ph.D. Thesis, University College Cork, Cork (2010)

30. Kearney, D.: Beyond location: the relevance of regional identities in Irish traditional music. Sonus 33(1), 1-20 (2012)

31. Keegan, N.: The verbal context of style in traditional Irish music. In: O’Suillebháin, M., Smith, T. (eds.) Selected Proceedings from Blas: The Local Accent in Irish Traditional Music

32. Keegan, N.: The words of traditional flute style. M.A. Thesis, University College Cork, Cork, Ireland (1992)

33. Keegan, N.: The verbal context of regional style in traditional Irish music. Blas: the local accent in Irish traditional music (1997)

34. Keegan, N.: The linguistic turn at the turn of the tune: the language of 'contemporary ensemble' in Irish traditional music. Ethnomusicol. Ireland 1, 37-48 (2011)

35. Keegan, N.: The art of juncture: transformations of Irish traditional music (Unpublished). Ph.D. Thesis, Limerick (2012)

36. Köküer, M., Jančovič, P., Ali-MacLachlan, I., Athwal, C.: Automatic detection of single and multi-note ornaments in Irish traditional flute playing. In: Proceedings of the 15th International Society for Music Information Retrieval Conference (ISMIR), Taipei, Taiwan, pp. 15-20 (2014)

37. Köküier, M., Kearney, D., Ali-MacLachlan, I., Jančovič, P., Athwal, C.: Towards the creation of digital library content to study aspects of style in Irish traditional music. In: Proceedings of the International Workshop on Digital Libraries for Musicology (DLfM), London (2014)

38. Larsen, G.: The Essential Guide to Irish Flute and Tin Whistle. Mel Bay Publications, Pacific (2003)

39. Larsen, G.: Grey Larsen biography. http://greylarsen.com/press/ biography/\#longbio (2013). Accessed 20 June 2014

40. Lomax, A.: Cantometrics: An Approach to the Anthropology of Music. University of California, Extension Media Center, Berkeley (1976)

41. Lyth, D.: Bowing Styles in Irish Fiddle Playing. Comhaltas Ceoltir Éireann, Dublin (1981)

42. Lyth, D.: Bowing Styles in Irish Fiddle Playing, vol. 2. Comhaltas Ceoltir Éireann, Dublin (1996)

43. Mauch, M., Cannam, C., Bittner, R., Fazekas, G., Salamon, J., Dai, J., Bello, J., Dixon, S.: Computer-aided melody note transcription using the Tony software: accuracy and efficiency. In: International Conference on Technologies for Music Notation and Representation (TENOR), pp. 23-30 (2015)

44. Mauch, M., Dixon, S.: pYIN: A fundamental frequency estimator using probabilistic threshold distributions. In: IEEE International Conference on Acoustics, Speech and Signal Processing (ICASSP), pp. 659-663 (2014)

45. McCormack, J.: Fliúit: Irish Flute Tutorial. June McCormack (2006)

46. McCormack, J.: Fliúit 2: flute tutorial for intermediate \& advanced players. June McCormack (2009)

47. Mitchell, P.: The Dance Music of Seamus Ennis. Na Pobair Uilleann, Dublin (2007)

48. Canainn, T.Ó.: Traditional Music in Ireland. Routledge and Kegan Paul, London (1978)

49. O'Connor, N.: Bringing It All Back Home: The Influence of Irish Music. BBC Books, London (1991)

50. O’Gráda, C.: An Fheadóg Mhór : Irish Traditional Flute Technique. Daorla Publications, Cork (2011)

51. O'Shea, H.: The Making of Irish Traditional Music. Cork University Press, Cork (2008)

52. O'Suillebháin, M.: Creative process in Irish traditional dance music. Irish Musical Studies 1: Musicology in Ireland (1) (1990)

53. Playford, J.: Playford's Dancing Master. Faber Music Ltd, London (2007)

54. Riada, S.Ó., Kinsella, T., Canainn, T.Ó.: Our Musical Heritage. Dolmen Press, Dublin (1982) 
55. Rosinach, V., Traube, C.: Measuring swing in Irish traditional fiddle music. In: Proceedings of International Conference on Music Perception and Cognition, pp. 1168-1171 (2006)

56. Sun, X.: Pitch determination and voice quality analysis using Subharmonic-to-Harmonic Ratio. In: Proceedings of IEEE International Conference on Acoustics, Speech, and Signal Processing, vol. 1, pp. 333-336 (2002)

57. TradConnect. Gradam Ceoil TG4: Interview with Harry Bradley, Posted on March 10, 2014. http://tradconnect.com/profiles/blogs/ gradam-ceoil-tg4-interview-with-harry-bradley. Accessed $20 \mathrm{Jan}$ 2016

58. Vallely, F.: Timber: The Flute Tutor. Waltons, Dublin (1986/2013)

59. Vallely, F.: Flute routes to 21 st century Ireland: the history, aesthetics and social dynamics of three centuries of recreational and political music. M.A. Thesis, University College Dublin, Dublin, Ireland (2005)
60. Vallely, F.: The Companion to Irish Traditional Music. Cork University Press, Cork (2011)

61. Wilkinson, D.: Play me a lonesome reel : factors relating to the building of a musical style and the social reality of performance in the Sligo/Leitrim region of north west Connaught Belfast. M.A. Thesis, Queens University Belfast (1991)

62. Williams, S.: Irish Traditional Music. Routledge, Abingdon (2010)

Publisher's Note Springer Nature remains neutral with regard to jurisdictional claims in published maps and institutional affiliations. 